\title{
1 Technical and environmental improvement of the \\ 2 bleaching sequence of dissolving pulp for fibre \\ 3 production
}

4 C. Arce ${ }^{1}$, T. Llano ${ }^{1}$, P. García ${ }^{1}$, A. Coz (corresponding) ${ }^{1}$

$5 \quad{ }^{1}$ Department of Chemistry and Process \& Resource Engineering, green Engineering 6 and Research Group (www.geruc.es). University of Cantabria, Avda Los Castros s/ $n$,

$7 \quad$ Santander 39005 Cantabria, Spain. coza@unican.es.

\section{Abstract}

9 Reactivity of dissolving pulp is one of the main parameters to determine its availability to be transformed 10 into viscose. It is related to the use of carbon disulphide $\left(\mathrm{CS}_{2}\right)$. An industrial sequential totally chlorine free 11 bleaching process is used as case study. It is carried out in two stages: 1) Alkaline extraction (EOP) and 2) 12 peroxide bleaching (PO). In order to assess how to decrease the use of carbon disulphide, several 13 experiments were performed at laboratory scale for the two stages mentioned before by modifying the 14 operating conditions: $\mathrm{NaOH}$ and $\mathrm{H}_{2} \mathrm{O}_{2}$ dosages, time and temperature. Reactivity using a modified Fock's 15 method and pentosan content was analysed along with quality pulp parameters: $\alpha$-cellulose, viscosity and 16 lignin content (kappa number). Results showed that reactivity increases through the bleaching process and 17 varies with the chemical dosage in both stages. Pulp obtained at the best conditions had the following 18 characteristics: reactivity, $95.3 \%$; $\alpha$-cellulose $91.17 \%$; intrinsic viscosity, $448 \mathrm{~mL} / \mathrm{g}$; kappa number, 1.81 19 and pentosan content $2.86 \%$, and as a result, $\mathrm{CS}_{2}$ usage was reduced by $11.88 \%$. At the best conditions 20 obtained in this work, $\mathrm{NaOH}$ dosage in $\mathrm{PO}$ stage was reduced to zero and temperature was slightly lower, 21 when compared with industrial operating conditions.

22 Keywords: TCF bleaching, Fock's reactivity, viscose, pentosan, dissolving pulp 


\section{INTRODUCTION}

24 Dissolving pulp is a high-grade cellulose pulp (90\% to $98 \%$ cellulose content), with low contents of hemicellulose, lignin and resin, and can achieve very high brightness (> $90 \%$ ISO). The market demand for this material has been constantly growing around the world for the past decade, particularly in China (Llano et al. 2017). It can be also transformed into a wide variety of products that can be used in applications such as food packaging, additives, filters, clothing and paints (Strunk 2012). The most widely used raw material to produce dissolving pulp is wood, about $85 \%$ of it is produced from this lignocellulosic material (Li et al. 2018a); either softwood or hardwood (Chen et al. 2016).

The main production processes of dissolving pulp are pre-hydrolysis Kraft (PHK) and Acid Sulphite (AS) (Sixta et al. 2013). In fact, AS dissolving pulp represents the $42 \%$ of the worldwide production (Brice 2012), although there are others such as $\mathrm{SO}_{2}$-ethanolwater process (Iakolev et al. 2011; Yahamoto et al. 2014; Yadollahi et al. 2018), prehydrolysis soda-anthraquinone (Sixta and Schild, 2009) or by even purification of paper grade pulp (Duan et al. 2014).

The global production of dissolving pulp in 2015 was 7.5 million tons (Yang et al. 2018) and being viscose the main end-product from dissolving pulp from any feedstock either woody or residual lignocellulosic material. According to (Kumar, H. et al. 2017) over 70 $\%$ of the dissolving pulp is used for viscose production. Particularly, in China the production of viscose fibre, in 2012, represented the $62 \%$ of the viscose production worldwide (Chen et al. 2016). Viscose process involves several steps to transform dissolving pulp into fibre (Lewin 2006). One of the most important steps involved in the process is xanthation. In this part of the process, carbon disulphide $\left(\mathrm{CS}_{2}\right)$ is used to dissolve cellulose and obtain the viscose solution which will be later transformed into viscose fibres. This compound is toxic and flammable (Sachin et al. 2019). Therefore, efforts need to be taken in order to reduce the consumption of $\mathrm{CS}_{2}$ to make viscose industry environmentally friendlier.

In order to obtain a high-quality dissolving pulp to be used to produce viscose fibre, pulp needs to be purified. After its production, pulp is sent then through the bleaching process, which objective is not only to increase brightness but also to increase purity, removing lignin and hemicelluloses, adjusting the viscosity and molecular weight distribution of the cellulose (Liu et al. 2016). Such improvements on pulp quality allows it to meet the 
requirements of end-use products such as viscose, acetates, cellulose nitrate or cellulose ether ( $\mathrm{Ji}$ et al. 2015). The main bleaching sequences can be classified as: elemental chlorine (EC) (Tripathi et al. 2018); elemental chlorine free (ECF) (Kaur et al. 2018; Jour et al. 2015) and totally chlorine free (TCF) (Li et al. 2018b; Bahrami et al. 2018). EC bleaching uses chlorine-based compounds to perform the purification process (Sixta, 2006). Despite the advantages of these compounds, such as selectivity towards lignin elimination and low cost, they contribute to the formation of halides, which has a negative impact to the environment. Therefore, research on alternatives bleaching sequences started to gain attention and, as a result, chlorine-based sequences began to be replaced by oxygen-based sequences (Fardim, 2011). The main alternatives developed were ECF and TCF bleaching sequences. On one hand, ECF technology replaces $\mathrm{Cl}_{2}$ by other compounds that are not as harmful, however it still uses $\mathrm{ClO}_{2}$ as main bleaching agent, research of this kind of technology focuses on reducing the quantity of this compound using additional treatments (Loureiro, 2010; Huang et al. 2012; Salazar et al. 2012). On the other hand, TCF bleaching replaces all chlorine-based compounds with oxygen-based ones such as: Ozone, oxygen, sodium hydroxide and oxygen peroxide. The main advantage of TCF sequences is that they have a lower environmental impact than ECF or EC sequences, however one disadvantage is that selectivity towards impurities is not as high as ECF or EC. Several properties of the pulp were measured to evaluate the pulp: $\alpha$ cellulose content, pentosan content, viscosity, lignin content. In fact, three of these properties are considered in the standard FZ/T 51001-2009 as quality parameters of wood pulp for viscose fibre which are: pentosan content, viscosity and $\alpha$-cellulose content, among others. $\alpha$-cellulose content needs to be higher than $90 \%$, since this is the fraction of the pulp that will be transformed into viscose fibres, viscosity of pulp gives the fibre the strength needed and pentosan need to be as lower as possible, because it may interfere in the conversion of pulp into viscose, lowering the yield obtained.

Due to the influence of several parameters on the reactivity of dissolving pulp towards viscose, such as the orientation of cellulose (cellulose I parallel or cellulose II, antiparallel) and morphology of the fibre (high porosity, pore volume, thickness of the cell wall or surface area), different methods have been carried out to measure it, such as: iodine sorption (Haule, 2016), NMR spectroscopy (Christoffersson et al. 2002), viscose filterability (Gehmayr et al. 2011), (Wu et al. 2014) and Fock test (Tian et al. 2014); (Ibarra et al. 2010); (Duan et al. 2016). According to Duan et al. (2015) the last two 
analysis have a good correlation between them but, even though Fock's test takes some time to be done, it does not require complex equipment to be performed in comparison with the viscose filterability (Chao et al. 2014) and uses a smaller amount of pulp (Köpke, 2010). For all of the reasons mentioned previously, several authors have used Fock's reactivity test recently: (Borrega et al. 2018; Sango et al. 2018; Wang et al. 2018). This method is a microscale viscose process that measures the quantity of reacted cellulose after xanthantion with $\mathrm{CS}_{2}$ under alkaline conditions (Quintana et al. 2015); therefore, the influence of the different parameters in the bleaching sequence can be assessed by this method. In addition, other quality parameters in the final dissolving pulp need to be also analysed.

There are several studies that focus on improving the reactivity of dissolving pulp (Li et al. 2018a) by: mechanical treatment, breaking or removing the primary cell wall and shortening the cellulose chains (Grönqvist et al. 2014; Wu et al. 2014: Zhao et al. 2017), enzymatic treatment, removing the hemicelluloses and adjusting the viscosity (Martínez 2016; Payne et al. 2015) or Ionic liquids extraction, extracting hemicelluloses without almost no elimination of cellulose with the addition of water (Roselli et al. 2014; Zhu et al. 2014). However, no research has been found on how the bleaching operating conditions affect the reactivity of the pulp, furthermore the enhancement of the reactivity was always performed either on the final product or as a treatment prior to the bleaching process. Because of this, efforts focused on trying to improve reactivity of the pulp during two-stages of TCF bleaching need to be taken. Therefore, the aim of this work is to assess how Fock's reactivity and pentosan content evolve with the operating conditions, $\alpha$ cellulose content, viscosity and lignin content (kappa number) were also determined to validate the operating conditions. The reduction of the usage of $\mathrm{CS}_{2}$ in the viscose process, based on reactivity, is also evaluated. Taking this into account, recommendations on the industrial operating conditions can be given, to improve the quality of dissolving pulp to be converted into viscose, without any additional stage or requirement. 


\section{MATERIALS AND METHODS}

\section{Pulp samples and preparation}

117 Pulp used in the bleaching experiments was obtained from a dissolving pulp factory 118 located in Northern Spain, from the inlet alkaline extraction (EOP) and peroxide 119 bleaching (PO). Table 1 shows the inlet quality values of the pulp for each stage.

The industrial scale bleaching process is based on the following TCF sequence: Ozone (Z)-Alkaline extraction (EOP)-Peroxide oxidation (PO). Pulp used in this work as raw material, was already ozonised. After the bleaching process, dissolving pulp meets the quality requirements to be used as raw material for viscose purposes. Prior to make any analysis, the pulp handsheets were prepared as described in TAPPI T205 sp-02 standard (2002). Cellulose pulp was disintegrated in a rotary stirrer to homogenise the sample, filtered with a Büchner funnel and oven dried at $105^{\circ} \mathrm{C}$. Afterwards, pulp handsheets were left to get moisture equilibrium in the air atmosphere. All the analysis was performed in triplicate.

\section{Bleaching Procedure}

136 The methodology used in this work is the one previously utilized by the authors in, Llano 137 et al. (2018) for the optimisation of the TCF bleaching sequence in four different scenarios. Pulp used in EOP and PO experiments were carried out in $1 \mathrm{~L}$ stainless steels vessels. EOP uses $\mathrm{NaOH}$ as main bleaching compound, boosted by the addition of $\mathrm{H}_{2} \mathrm{O}_{2}$ and $\mathrm{PO}$ uses $\mathrm{H}_{2} \mathrm{O}_{2}$ as main bleaching agent, coupled with the addition of $\mathrm{NaOH}$, both stages are pressurised with oxygen. Inlet pulp was washed with tap water, until the

142 wastewater $\mathrm{pH}$ was 7. Pulp was then hand dried and kept in the refrigerator to avoid any

143 further degradation (Yaqoob et al. 2010). Firstly, moisture content of the pulp is measured 144 and then $300 \mathrm{~g}$ of pulp, calculated as oven dried (o.d.), is weighed. Then hot water, between $65-70{ }^{\circ} \mathrm{C}$, is added to the pulp to obtain a moisture content of $11 \%$. Finally, the 
146 reactants are added, the quantity depends on the experiment carried out. The vessel is then

147 pressurised with oxygen at 1.65 bar (EOP stage) and 2.5 bar (PO). When the reaction

148 finishes the pulp is retrieved from the reactor and washed until the $\mathrm{pH}$ of the washing

149 wastewater is 7.

\section{Pulp Analysis}

\section{Fock reactivity}

152 Reactivity of pulp samples was measured by the method described by Tian et al (2013)

153 which is based on Fock (1959).

154 First, $0.5 \mathrm{~g}$ of pulp calculated as oven dried (o.d.) were weighed and put into a $250 \mathrm{~mL}$ 155 Erlenmeyer flask. Then, $50 \mathrm{~mL}$ of $\mathrm{NaOH} 9 \%(\mathrm{w} / \mathrm{w})$ were added and stirred for $10 \mathrm{~min}$ at $15619^{\circ} \mathrm{C} .1 .3 \mathrm{~mL}$ of $\mathrm{CS}_{2}$ were added, sealed with plastic parafilm and stirred at $250 \mathrm{rpm}$ for

$1573 \mathrm{~h}$ at $19^{\circ} \mathrm{C}$. This is the xanthation phase in which cellulose-xanthate is formed. When 158 reaction time finishes, water was added until a total mass of $100 \mathrm{~g}$, the solution was then 159 agitated and centrifuged at $5000 \mathrm{rpm}$ for $15 \mathrm{~min}$. Afterwards, $10 \mathrm{~mL}$ of the supernatant 160 were poured in a $100 \mathrm{~mL}$ flask and $3 \mathrm{~mL}$ of sulphuric acid $20 \%$ (w/w) was added to 161 regenerate the dissolved cellulose. The flasks were left in a fume hood for $15 \mathrm{~h}-20 \mathrm{~h}$ for 162 the $\mathrm{CS}_{2}$ excess to be removed.

163 Dissolved cellulose was measured by oxidation with $\mathrm{K}_{2} \mathrm{Cr}_{2} \mathrm{O}_{7}$. Firstly, $20 \mathrm{~mL}$ of sulphuric 164 acid $68 \%(\mathrm{w} / \mathrm{w})$ were added and stirred at $250 \mathrm{rpm}$ for $1 \mathrm{~h}$. When stirring time was set, $16510 \mathrm{~mL}$ of $1 / 6 \mathrm{M} \mathrm{K}_{2} \mathrm{Cr}_{2} \mathrm{O}_{7}$ was added and the mixture was reflux-boiled for $1 \mathrm{~h}$. Finally, 166 the flasks were left to cool at room temperature, and then diluted to a total volume of 100 167 mL. $40 \mathrm{~mL}$ of the solution were pipetted into a $250 \mathrm{~mL}$ Erlenmeyer flask and $5 \mathrm{~mL}$ of 10 $168 \%(\mathrm{w} / \mathrm{w}) \mathrm{KI}$ were added and titrated with $0.1 \mathrm{~N}$ sodium thiosulfate using starch as 169 indicator. The volume of sodium thiosulfate was used for the calculation of the dissolved 170 cellulose (DC) using Eq. (1):

$$
\operatorname{DC}(\%)=\frac{\left[\mathrm{v}_{1} \cdot \mathrm{c}_{1}-\left(\mathrm{v}_{2} \cdot \mathrm{c}_{2} \cdot \frac{100}{40}\right) \cdot \frac{1}{6}\right] \cdot \mathrm{M} \cdot \frac{1}{4} \cdot \frac{100}{10.4}}{\mathrm{~m}} \cdot 100
$$

172 Where $\mathrm{M}$ is the molecular weight of a glucose unit, $\mathrm{m}$ is the o.d. weight of the pulp sample

$173(\mathrm{~g}), \mathrm{v}_{1}$ and $\mathrm{c}_{1}$ are the volume and the concentration of $\mathrm{K}_{2} \mathrm{Cr}_{2} \mathrm{O}_{7}$, respectively. $\mathrm{v}_{2}$ and $\mathrm{c}_{2}$ are 174 the volume and the concentration of sodium thiosulfate respectively. 
176 The moisture content of the pulp was measured, $1.6 \mathrm{~g}$ of pulp was weighed and $100 \mathrm{~mL}$

177 of $\mathrm{NaOH} 5 \%(\mathrm{w} / \mathrm{w})$ was added. Then, it was stirred for 3 min and left in a water bath for

1781 hour, the suspension was filtered, and $15 \mathrm{~mL}$ of the filtrate were added to a $250 \mathrm{~mL}$

179 Erlenmeyer flask and mixed with $10 \mathrm{~mL}$ of $\mathrm{K}_{2} \mathrm{Cr}_{2} \mathrm{O}_{7}$ and $35 \mathrm{~mL}$ of $\mathrm{H}_{2} \mathrm{SO}_{4}$ were added. It

180 was left to cool for $15 \mathrm{~min}$ and $50 \mathrm{~mL}$ of distilled water were added. The solution was

181 titrated with $\left(\mathrm{NH}_{4}\right)_{2} \mathrm{Fe}\left(\mathrm{SO}_{4}\right)_{2} \cdot 6 \mathrm{H}_{2} \mathrm{O} 0.1 \mathrm{~N}$ using ferroin as indicator.

182 Intrinsic Viscosity

183 Intrinsic viscosity was determined by the standard ISO 5351(2010). 0.25 g. oven-dried

184 pulp was dissolved in cupriethylendiamine solution for half an hour. After this, the sample

185 was left in a water bath at $25^{\circ} \mathrm{C}$ for 15 minutes and passed through Cannon-Fenske 150

186 viscometer at $25^{\circ} \mathrm{C}$.

187 Alpha-cellulose

188 Alpha-cellulose was determined according to TAPPI T203 cm-99 (1999). Oven-dried

189 pulp samples were weighed to an equal of 1.6 $\pm 0.1 \mathrm{~g}$. Pulp was consecutively extracted

190 with $17.5 \% \mathrm{NaOH}$ solutions at $25 \pm 0.2{ }^{\circ} \mathrm{C}$ for a total extraction time of $60 \pm 5 \mathrm{~min}$. Then,

191 pulp samples were stirred and filtered. $25 \mathrm{~mL}$ of the filtrate were taken and mixed with

$19210 \mathrm{~mL}$ of $0.5 \mathrm{~N} \mathrm{~K}_{2} \mathrm{Cr}_{2} \mathrm{O}_{7}$ and $50 \mathrm{~mL}$ of $96 \% \mathrm{H}_{2} \mathrm{SO}_{4}$. After 15 minutes, samples were

193 cooled by adding $50 \mathrm{~mL}$ of water and titrated with $0.1 \mathrm{~N}\left(\mathrm{NH}_{4}\right)_{2} \mathrm{Fe}\left(\mathrm{SO}_{4}\right)_{2} \cdot 6 \mathrm{H}_{2} \mathrm{O}$ using

194 ferroin indicator.

195 Kappa

196 Kappa is an index that estimates the amount of residual lignin and hexenuronic acid by

197 measuring the oxidant demand of the pulp. TAPPI UM 246 (1991) method was

198 implemented in order to obtain the micro kappa number of high-purity pulp from the final

199 stages of the bleaching process.

200 CS $_{2}$ consumption calculation

$201 \mathrm{CS}_{2}$ consumption was calculated using Fock reactivity, $\alpha$-cellulose content and the 202 stoichiometric value required for the xanthation phase $(23.5 \% \mathrm{w} \mathrm{CS} / \mathrm{w}$ cellulose) 203 (Gondhalekar et al. 2019). Considering Fock's reactivity as a reaction yield of xanthation 
and the $\alpha$-cellulose content of the pulp, the theoretical quantity of fibres (TF) is obtained using equation 2. The $\mathrm{CS}_{2}$ consumption is calculated using the stoichiometric value of $206 \mathrm{CS}_{2}$ and $\alpha$-cellulose content (equation 3 ).

$$
\mathrm{TF}(\%)=\frac{\alpha \text {-cellulose }(\%) \cdot \text { Reactivity }(\%)}{100}
$$

$$
\mathrm{CS}_{2} \text { usage }(\%)=\frac{\alpha-\text { cellulose }(\%) \cdot 23.5}{100}
$$

The quantity of $\mathrm{CS}_{2}$ used to obtain viscose need to be calculated not only taking into account the reactivity of the sample but also the quantity of total fibre in the sample

211 because it depends on the alpha-cellulose content. Therefore, a $\mathrm{CS}_{2}$ usage /TF ratio, called ratio of consumption per fibre $(\mathrm{RCF})$ was measured and then, with the objective of comparing all of the results, the final reduction of $\mathrm{CS}_{2}$ usage was calculated using as reference the ratio RCF from the inlet pulp.

$$
\mathrm{RCF}=\frac{\mathrm{CS}_{2} \mathrm{usage}(\%)}{\mathrm{TF}(\%)}
$$

\section{Results}

\section{Study of the influence of the operating conditions on reactivity and} 219 pentosan content

220 Figure 1 shows the influence of the operating conditions $\left(\mathrm{NaOH}\right.$ and $\mathrm{H}_{2} \mathrm{O}_{2}$ dosages, time and temperature) over pulp reactivity in both EOP and PO stages. Square and triangle shaped points represent the best value of the operating conditions studied for EOP and

223 PO stage respectively and was fixed for the following experiments. To choose these 224 conditions, not only reactivity and pentosan content values were considered, also $\alpha-$ 225 cellulose content, viscosity and kappa number were considered.

226 Figure 1a shows the influence of $\mathrm{NaOH}$ dosage on pulp reactivity. In the EOP stage, 227 reactivity increases while $\mathrm{NaOH}$ dosage increases, reaching a maximum of $70 \%$ at 70 $228 \mathrm{~kg} / \mathrm{ADT}$ (Air Dried Tonnes), further increasing the dosage of $\mathrm{NaOH}$ leads to a reduction 229 in reactivity. (H. Wang et al. 2014), reported this reduction as a result of the hornification 230 effect, which reduces the pore volume of the pulp and the accessibility of the chemicals 231 (Dinand et al. 2002). Rebuzzi et al (2006), found a relationship between pentosan content 
232 and hornification, when using $10 \% \mathrm{KOH}$ extraction, the higher the pentosan content the

233 lower the hornification. On the other hand, Kaur et al (2017), found that alkali dose higher

234 than $8 \%$ increases the hornification effect, which can be seen in the experiments when 90

$235 \mathrm{~kg} / \mathrm{ADT}$ of $\mathrm{NaOH}(9 \% \mathrm{w} / \mathrm{w})$ was used, both trends are in accordance with this study.

236 Recent studies also reported that increasing $\mathrm{NaOH}$ makes cellulose I (parallel orientation)

237 transform into cellulose II (antiparallel orientation), and as a result, reactivity is lower ( $\mathrm{Li}$

238 et al. 2018a). Therefore, an excess of $\mathrm{NaOH}$ is undesirable to obtain a good quality pulp

239 to be processed into viscose. In fact, when no $\mathrm{NaOH}$ is used high reactivity pulp is

240 obtained (>90\%), showed by the triangle in figure 1.a. As a result, the addition of $\mathrm{NaOH}$

241 in the PO stage might be eliminated, reducing the quantity of chemicals used, in the

242 bleaching process, and economic and environmental impacts.

243
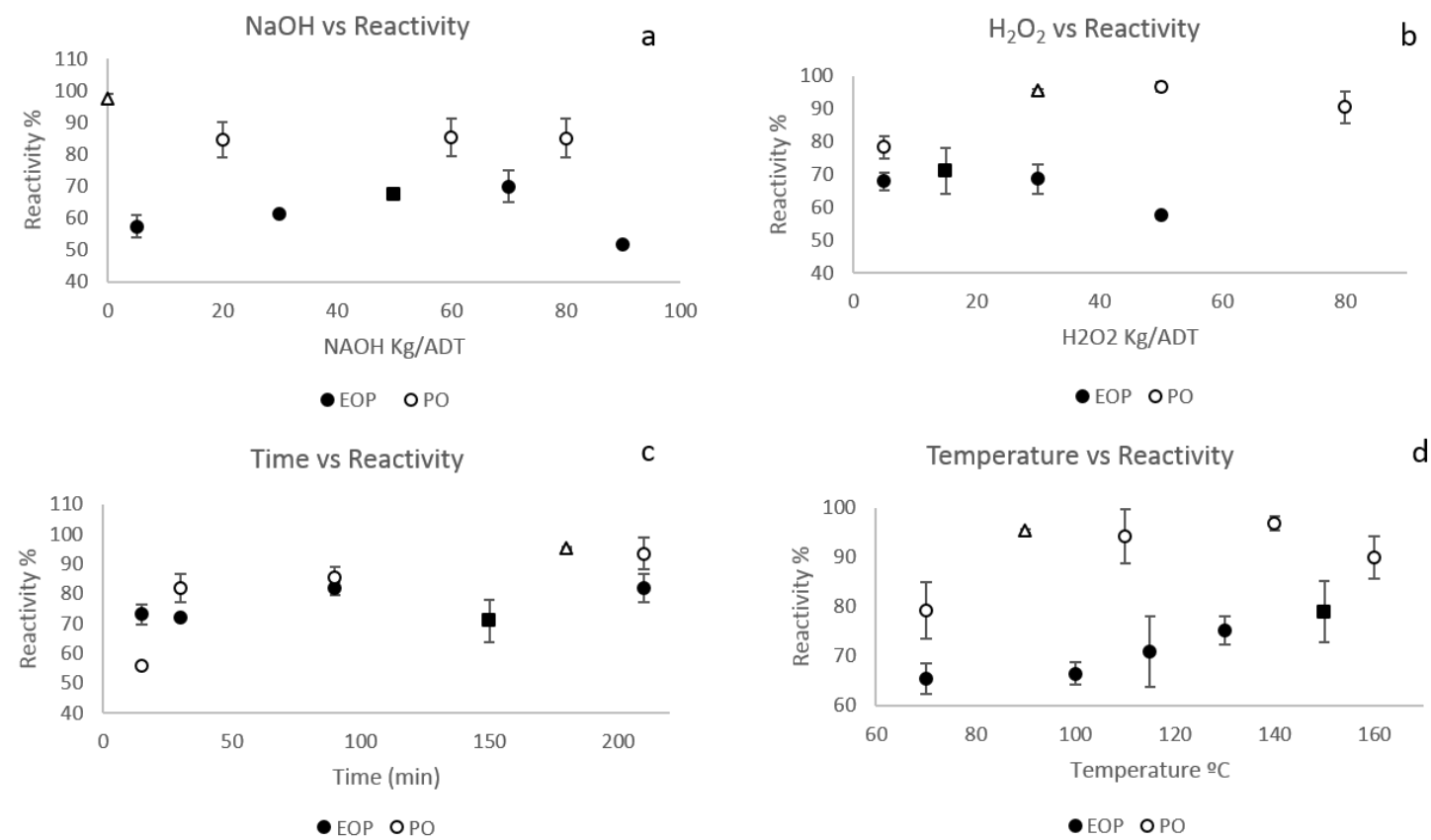

245 Figure 1 Influence of the process variables on reactivity: a) $\mathrm{NaOH}$ dosage (kg/ADT), b) $\mathrm{H}_{2} \mathrm{O}_{2}$ dosage 246 (kg/ADT), c) time (min) and d) Temperature $\left({ }^{\circ} \mathrm{C}\right)$

247 The effect of $\mathrm{H}_{2} \mathrm{O}_{2}$ is shown in figure 1 (b). In the PO stage reactivity increases initially 248 until $30 \mathrm{~kg} /$ ADT, further increasing the dosage of $\mathrm{H}_{2} \mathrm{O}_{2}$ lead to poor reactivity values, 249 even below inlet pulp values. $\mathrm{H}_{2} \mathrm{O}_{2}$ degrades the cellulose chain making it more accessible 250 for chemicals to react, as a result of the degradation of the surface of the fibrils (Strunk et 251 al. 2012). Although further increasing $\mathrm{H}_{2} \mathrm{O}_{2}$ dosage might lead to good reactivity, poor viscosity values, below $400 \mathrm{~mL} / \mathrm{g}$ are obtained, which are undesirable. In fact, at 50 
$253 \mathrm{~kg} / \mathrm{ADT}$ and $80 \mathrm{~kg} / \mathrm{ADT}$, good reactivity values are obtained, however viscosity values

254 were $328 \mathrm{~mL} / \mathrm{g}$ and $295 \mathrm{~mL} / \mathrm{g}$ respectively, leading to low quality viscose.

255 The effects of time and temperature on reactivity are shown in figures 1.c and 1.d 256 respectively. Time has a similar effect on both bleaching stages, in the EOP stage when 257 time is below $50 \mathrm{~min}$, there is no increase of reactivity, however residence times higher 258 than 50 min caused reactivity increases up to $81 \%$ to remain constant for higher reaction 259 times (higher than $100 \mathrm{~min}$ ).

260 For the PO stage kinetics are faster than for EOP stage. In fact, below 40 min reactivity 261 reaches a nearly constant value to increase when time is set to $210 \mathrm{~min}$. In regards of 262 temperature, it has a positive effect on reactivity on both stages. In the EOP stage, 263 reactivity does not increase until temperature reaches a value higher than $100^{\circ} \mathrm{C}$ to reach 264 the equilibrium at $130{ }^{\circ} \mathrm{C}$, meaning that further increasing temperature would not increase 265 reactivity. Pulp in the PO stage behave differently, reactivity remains constant until 110 $266{ }^{\circ} \mathrm{C}$, and increasing temperature increases reactivity up to a value higher than $90 \%$ at 140 $267{ }^{\circ} \mathrm{C}$. However, when temperature is higher than $140{ }^{\circ} \mathrm{C}$ reactivity decreases. This effect is 268 produced by the degradation of hemicelluloses, (Kolar 1997). Besides, a research study 269 stated that at studied temperatures, some of the glycosidic bonds are broken, thus pentosan 270 content increases (Sixta 2006). Pentosans react with $\mathrm{NaOH}$ used in the production of 271 viscose and compete with cellulose.

272 Figure 2 shows the influence that the operating conditions: $\mathrm{NaOH}$ and $\mathrm{H}_{2} \mathrm{O}_{2}$ dosages, time 273 and temperature, both for the EOP and PO stages have on the pentosan content. 

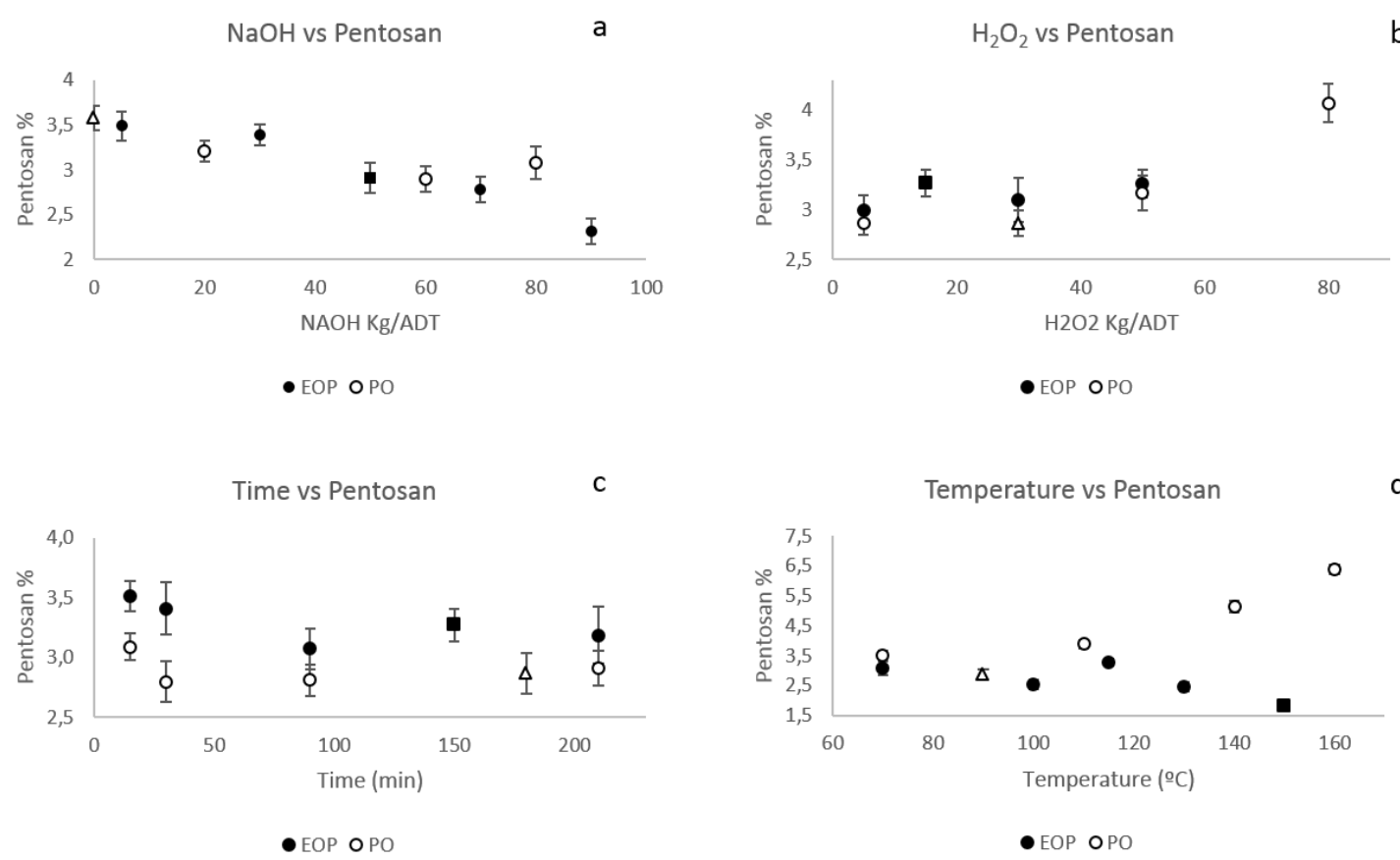

- EOP OPO

Figure 2 Influence of the process variables on pentosan content: a) $\mathrm{NaOH}$ dosage (kg/ADT), b) $\mathrm{H} 2 \mathrm{O} 2$ dosage $(\mathrm{kg} / \mathrm{ADT}), \mathrm{c})$ time $(\mathrm{min})$ and $\mathrm{d})$ Temperature $\left({ }^{\circ} \mathrm{C}\right)$

278 As shown in figure 2.a, pentosan content decreases with the addition of $\mathrm{NaOH}$, since 279 hemicellulose and pentosan are known to be dissolved by $\mathrm{NaOH}$. In the PO stage, 280 pentosan content decreases with the addition of $\mathrm{NaOH}$ until $60 \mathrm{~kg} / \mathrm{ADT}$ are used, where 281 it reaches a minimum of $2.98 \%$. Pulp quality requires pentosan content to be below $4 \%$ 282 (FZ/T 51001-2009), therefore it is in accordance within the range studied. Figure 2.b, 283 shows the evolution of the pentosan content with the $\mathrm{H}_{2} \mathrm{O}_{2}$. In the EOP stage pentosan content increases, because hydrogen peroxide reacts with hemicelluloses, thus liberating pentosan that cannot be dissolve by $\mathrm{NaOH}$. However, in the PO stage this parameter 286 remains constant until $30 \mathrm{~kg} / \mathrm{ADT}$ and it increases for higher dosages. It has to be noted 287 that when varying $\mathrm{H}_{2} \mathrm{O}_{2}$ dosage, $\mathrm{NaOH}$ was not used, therefore the pentosan liberated by 288 the action of hydrogen peroxide could not be dissolved.

289 Pentosan content has a similar trend, in both stages, decreasing initially until reaching a 290 constant value, however kinetic is different between each other. On the one hand, in the 291 EOP stage, the equilibrium is achieved for reaction times lower than $100 \mathrm{~min}$ and, on the 292 other hand, for the PO stage, the equilibrium is achieved at a reaction time of $30 \mathrm{~min}$, 293 therefore, pentosan kinetics in the PO stage are faster than in EOP stage.

294 Temperature has nearly no effect on pentosan content in the EOP stage, however in the 295 PO stage the trend changes significantly for temperatures higher than $120{ }^{\circ} \mathrm{C}$. Pentosan 296 content increases up to $6.38 \%$, which is undesirable for pulp quality to be transformed 
297 into viscose. Hemicellulose released by the effect of temperature, cannot be removed 298 because no $\mathrm{NaOH}$ were used in these experiments. Therefore, it is recommended that in 299 the PO stage, temperature below $120^{\circ} \mathrm{C}$ to be used.

300 As can be seen on the graphs, reactivity is higher in the PO stage than on the EOP stages.

301 This is in agreement with the configuration of the bleaching sequence studied since the

302 PO stage is the last one that takes place in the industrial process. Therefore, the bleaching 303 process has a positive effect on pulp reactivity. However, this is not enough for a pulp to 304 be suitable for viscose production. $\alpha$-cellulose, pentosan content and viscose, need to meet 305 certain values. Additionally, reactivity of pulp in the EOP stage cannot be increased to 306 meet the required values for viscose purposes, which means that in order to obtain pulp 307 to be transformed into viscose, the two stages are needed.

308 To decide which operating variable affected pulp quality the most, a statistical analysis 309 was performed with Stat Graphics Centurion XVII.II. Figure 3 shows the response surface 310 obtained with the information provided by the program. 

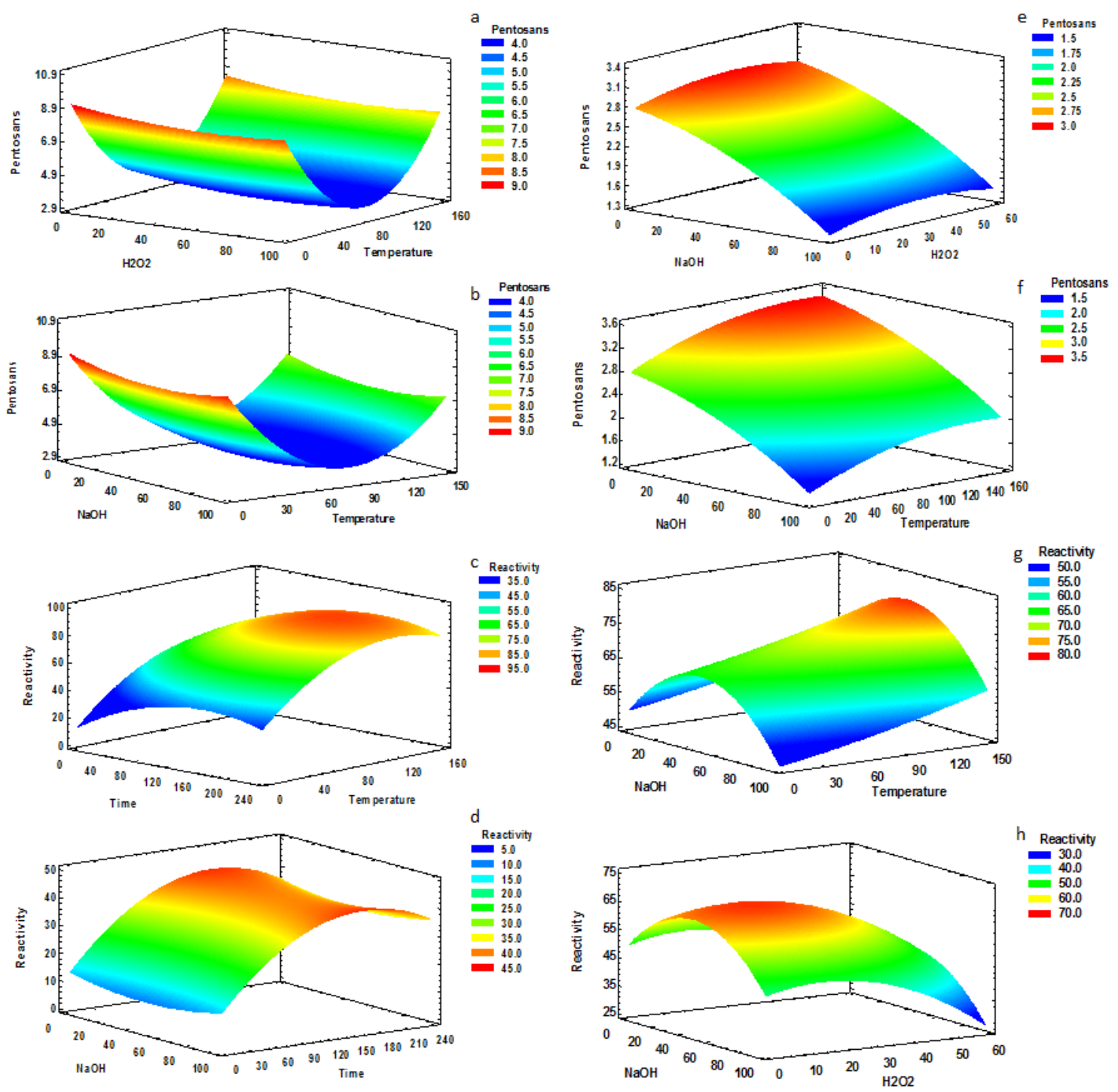

312 Figure 3 Response surfaces of the most affecting variables vs pentosan and reactivity: a), b), c), d) PO

313 stage and e), f), g), h) EOP stage

315 Regarding the PO stage, the variables that affect the most the pentosan content are 316 temperature, $\mathrm{H}_{2} \mathrm{O}_{2}$ and $\mathrm{NaOH}$ dosages (Figures 3.a and 3.b). As stated before, pentosan

317 content needs to be as lower as possible, so the blue range is the area for the adequate

318 pentosan content values. Therefore, mild conditions, regarding temperature, are

319 recommended, since the pentosan content remains low (4\%). This shows that the 320 degradation reaction of pentosan is temperature dependent. Figure 3.b shows the 321 evolution of pentosan with $\mathrm{NaOH}$ dosage and temperature, low temperature has no 322 significant effect on pentosan content, however combined with increasing dosages of $323 \mathrm{NaOH}$ pentosan content reduces to a minimum of $4 \%$, represented by the blue surface. 
324 Increasing temperature further leads to an increase in pentosan, but it degrades cellulose 325 so much that the released pentosan from hemicellulose cannot be eliminated by $\mathrm{NaOH}$.

326 Figures 3.c and 3.d show the dependence of reactivity with: time, temperature and $\mathrm{NaOH}$, 327 in the PO stage. Reactivity values need to be as high as possible, recommended values 328 have not been found on bibliography, however commercial dissolving pulp have about $32970 \%$ reactivity (Wang, $\mathrm{H}$. et al 2014), so recommended values should be chosen 330 following this condition. As can be seen in figure a.3, mild to high temperature conditions 331 are recommended, as reactivity higher than $90 \%$ can be achieved, shown by the red area. 332 Regarding $\mathrm{NaOH}$ dosage, reactivity above $45 \%$ cannot be achieved, this fact shows that $333 \mathrm{NaOH}$ does not affect reactivity as much as temperature does. Residence time of the 334 process should be established at between $120 \mathrm{~min}$ and $180 \mathrm{~min}$.

335 Regarding EOP stage, figures 3.e and 3.f represent the variation of the pentosan content 336 with temperature, $\mathrm{NaOH}$ and $\mathrm{H}_{2} \mathrm{O}_{2}$ dosages. On one hand pentosan decreases while 337 increasing $\mathrm{NaOH}$ dosage, since pentosan and hemicellulose are known to be dissolved by $338 \mathrm{NaOH}$. On the other hand, pentosan content increases while increasing $\mathrm{H}_{2} \mathrm{O}_{2}$ dosage. 339 However, when both compounds are added to the reactor, pentosan decreases (blue area). 340 Figure 3.f shows the effect of both $\mathrm{NaOH}$ dosage and temperature. High temperature 341 degrades cellulose and hemicellulose, releasing pentosan from the pulp. In fact, even 342 adding up to $100 \mathrm{~kg} / \mathrm{ADT}$, does not reduce pentosan content, as is it shown by the green 343 area. The recommended values are the ones which belong to the dark blue area, however 344 temperature needs to be at least $100{ }^{\circ} \mathrm{C}$, because some reactions are activated by 345 temperature.

346 Figures 3.g and 3.h, show the change of reactivity with the most affecting variables in the 347 EOP stage: temperature, $\mathrm{NaOH}$ and $\mathrm{H}_{2} \mathrm{O}_{2}$ dosage. As can be seen by figure 3.g, high and 348 low $\mathrm{NaOH}$ dosages results in low reactivity values, shown by the blue areas. At around $34950 \mathrm{~kg} / \mathrm{ADT}$ reactivity reaches a value of $65 \%$, represented by the light green area. 350 Increasing temperature, increase reactivity further, up to around $80 \%$, represented by the red area. Figure 3.h, shows the influence of the chemical compounds used in the bleaching sequence. As stated before, low and high $\mathrm{NaOH}$ dosages, result in low reactivity values around $50 \%$, represented by the green area. Mild dosage of $\mathrm{NaOH}$ is recommended in this stage about $50 \mathrm{~kg} / \mathrm{ADT}$. $\mathrm{H}_{2} \mathrm{O}_{2}$ dosage is recommended to be low, at about $15 \mathrm{~kg} / \mathrm{ADT}$, represented by the red area. Increasing the dosage further, leads to low reactivity. The dosage of the reactants $\left(\mathrm{H}_{2} \mathrm{O}_{2}\right.$ and $\left.\mathrm{NaOH}\right)$ were the most affecting variables for both, 
reactivity and pentosan content. In a previous study (Llano et al. 2018), chemical dosages were the most affecting parameters as well.

359 Therefore, recommended values of $\mathrm{NaOH}$ and $\mathrm{H}_{2} \mathrm{O}_{2}$ dosages would be $50 \mathrm{~kg} / \mathrm{ADT}$ and $36015 \mathrm{~kg} / \mathrm{ADT}$. Table 2 shows the values of the recommended operating conditions for these 361 bleaching stages.

Table 2 Recommended operating conditions for the EOP and PO stages, respectively.

\begin{tabular}{ccc}
\hline Variable & $\begin{array}{c}\text { Recommended } \\
\text { value }\end{array}$ & Units \\
\hline NaOH dosage & 50 & $\mathrm{~kg} / \mathrm{ADT}$ \\
$\mathrm{H}_{2} \mathrm{O}_{2}$ dosage & 15 & $\mathrm{~kg} / \mathrm{ADT}$ \\
Time & 150 & $\mathrm{~min}$ \\
Temperature & 150 & ${ }^{\circ} \mathrm{C}$ \\
\hline
\end{tabular}

\begin{tabular}{ccc}
\hline Variable & $\begin{array}{c}\text { Recommended } \\
\text { value }\end{array}$ & Units \\
\hline NaOH dosage & 0 & $\mathrm{~kg} / \mathrm{ADT}$ \\
$\mathrm{H}_{2} \mathrm{O}_{2}$ dosage & 30 & $\mathrm{~kg} / \mathrm{ADT}$ \\
Time & 180 & $\mathrm{~min}$ \\
Temperature & 90 & ${ }^{\circ} \mathrm{C}$ \\
\hline
\end{tabular}

364

365 Recommended values by this work are different from the values used in the industry,

366 which cannot be shown because they are confidential. The main difference from industrial

367 operating conditions are, that in the $\mathrm{PO}$ stage $\mathrm{NaOH}$ is used, however as can be seen in

368 table 2, recommended $\mathrm{NaOH}$ dosage in this stage is zero. It should be noted, that

369 operating conditions in the industry are sometimes adjusted, because raw material is 370 heterogeneous, regarding its properties. Therefore, pulp properties will also be different.

\section{$371 \quad$ CS $_{2}$ consumption}

372 As it was mentioned at the beginning of this work, $\mathrm{CS}_{2}$ is one of the main chemical 373 compounds used in the viscose industry. This compound is used in the xanthation stage 374 to dissolve alkali cellulose, which results in viscose, which will be later transformed in 375 viscose fibre or rayon. The quantity of this compound used in the industry ranges from $37632 \%$ to $34 \%$ w/w of cellulose (Gondhalekar et al. 2018). The use of this compound needs 377 to be controlled and, if possible, reduced, due to the environmental issues (Östberg et al. 378 2012). Table 3 shows the $\mathrm{CS}_{2}$ consumption in the PO stage. Negative values mean that 379 the consumption of $\mathrm{CS}_{2}$ is higher when compared with commercial values. Calculation is 380 done with equations 2 and 3.

$381 \mathrm{CS}_{2}$ consumption is calculated taking into account, not only the reactivity, but also the $\alpha-$ 382 cellulose content. It can be noted that the consumption is lower when operating conditions 383 are more severe. This is explained because reactivity increases when the pulp is more 
384 degraded. The operating conditions chosen as the best, are the ones that correspond to 385 experiment 4.2 , leading to a $\mathrm{CS}_{2}$ usage reduction of $11.88 \%$. This is not the higher 386 reduction obtained, however pulp parameters are in accordance with FZ/T 51001-2009, 387 for viscose purposes.

388 389 Table $3 \mathrm{CS}_{2}$ consumption in the PO stage.

\begin{tabular}{cccccccc}
\hline Experiment & $\begin{array}{c}\text { NaOH-kg/ADT } \\
\text { H2O2-kg/ADT } \\
\text { Time-min } \\
\text { Temperature- }\end{array}$ & $\begin{array}{c}\text { a-cellulose } \\
(\boldsymbol{\%})\end{array}$ & $\begin{array}{c}\text { Reactivity } \\
(\boldsymbol{\%})\end{array}$ & $\begin{array}{c}\mathbf{C S}_{\mathbf{2}} \\
(\boldsymbol{\%})\end{array}$ & $\begin{array}{c}\text { TF } \\
(\boldsymbol{\%})\end{array}$ & $\mathbf{R C F}$ & $\begin{array}{c}\mathbf{C S}_{2} \\
\text { reduction (\%) }\end{array}$ \\
\hline Commercial & - & 91.52 & $83.98 \pm 6.47$ & 21.51 & 76.85 & 0.28 & - \\
PO 1.1 & $0 / 0 / 180 / 90$ & 88.51 & $97.35 \pm 1.53$ & 20.80 & 86.16 & 0.24 & 13.74 \\
PO 1.2 & $20 / 0 / 180 / 90$ & 92.02 & $84.63 \pm 5.48$ & 21.62 & 77.88 & 0.28 & 0.770 \\
PO 1.3 & $60 / 0 / 180 / 90$ & 90.81 & $85.37 \pm 6.02$ & 21.34 & 77.52 & 0.28 & 1.630 \\
PO 1.4 & $80 / 0 / 180 / 90$ & 92.68 & $85.07 \pm 6.10$ & 21.78 & 78.84 & 0.28 & 1.280 \\
PO 4.1 & $0 / 5 / 180 / 90$ & 88.58 & $78.33 \pm 3.43$ & 20.82 & 69.38 & 0.30 & -7.210 \\
PO 4.2 & $0 / 30 / 180 / 90$ & 91.17 & $95.3 \pm 0.46$ & 21.42 & 86.89 & 0.25 & 11.88 \\
PO 4.3 & $0 / 50 / 180 / 90$ & 86.87 & $96.57 \pm 1.37$ & 20.41 & 83.89 & 0.24 & 13.04 \\
PO 4.4 & $0 / 80 / 180 / 90$ & 83.07 & $90.43 \pm 4.80$ & 19.52 & 75.12 & 0.26 & 7.130 \\
PO 2.1 & $0 / 30 / 15 / 90$ & 91.40 & $56.02 \pm 0.46$ & 21.48 & 51.20 & 0.42 & -49.91 \\
PO 2.2 & $0 / 30 / 30 / 90$ & 91.30 & $81.89 \pm 4.85$ & 21.46 & 74.77 & 0.29 & -2.550 \\
PO 2.3 & $0 / 90 / 90 / 90$ & 91.75 & $85.42 \pm 3.79$ & 21.56 & 78.37 & 0.28 & 1.690 \\
PO 2.4 & $0 / 30 / 210 / 90$ & 88.19 & $93.53 \pm 5.26$ & 20.72 & 82.48 & 0.25 & 10.21 \\
PO 3.1 & $0 / 30 / 180 / 70$ & 89.62 & $79.32 \pm 5.73$ & 21.06 & 71.09 & 0.30 & -5.870 \\
PO 3.2 & $0 / 30 / 180 / 110$ & 89.40 & $77.21 \pm 5.47$ & 21.01 & 69.03 & 0.30 & -8.770 \\
PO 3.3 & $0 / 30 / 180 / 140$ & 89.74 & $96.89 \pm 1.44$ & 21.09 & 86.95 & 0.24 & 13.33 \\
PO 3.4 & $0 / 30 / 180 / 160$ & 89.81 & $89.94 \pm 4.35$ & 21.11 & 80.78 & 0.26 & 6.630 \\
\hline
\end{tabular}

390

\section{CONCLUSIONS}

392 In this work, a study of pulp reactivity along a TCF bleaching sequence and its effect

393 through the operating conditions was carried out. High $\mathrm{NaOH}$ dosage leads to poor

394 reactivity values. At the recommended operating conditions values, reactivity can 395 increase up to $95.3 \%$ leading to a reduction of $\mathrm{CS}_{2}$ usage reduction of $11.88 \%$. The most 396 affecting operating conditions to reactivity in the EOP stage are, $\mathrm{NaOH}$ dosage and 397 temperature and in the PO stage are time and temperature. Regarding pentosan content, 398 in the EOP stage $\mathrm{NaOH}$ and $\mathrm{H}_{2} \mathrm{O}_{2}$ are the most affecting conditions and in the $\mathrm{PO}$ stage 399 are $\mathrm{H}_{2} \mathrm{O}_{2}$ and temperature. From this study it can be concluded that the two bleaching 
400

401

402

403

404

405

406

407

408

409

410

412

413

414

415

416

417

418

419

420

421

422

423

424

425

426

427

428

429

430

431

432

stages are needed in order to obtain a good pulp quality. However, both of these can be improved according to this paper to the following recommended values: in the EOP stage, $\mathrm{NaOH}$ dosage $50 \mathrm{~kg} / \mathrm{ADT} ; \mathrm{H}_{2} \mathrm{O}_{2} 15 \mathrm{~kg} / \mathrm{ADT} ; 150 \mathrm{~min} ; 150^{\circ} \mathrm{C}$ and in the $\mathrm{PO}$ stage, $\mathrm{NaOH}$ dosage $0 \mathrm{~kg} / \mathrm{ADT} ; \mathrm{H}_{2} \mathrm{O}_{2} 30 \mathrm{~kg} / \mathrm{ADT} ; 180 \mathrm{~min} ; 90^{\circ} \mathrm{C}$. Pulp obtained at the best conditions had the following characteristics: $\alpha$-cellulose content, $91.17 \%$; intrinsic viscosity, 448 $\mathrm{mL} / \mathrm{g}$; kappa number, 1.81 ; reactivity, $95.3 \%$ and pentosan content $2.86 \%$.

\section{ACKNOWLEDGEMENTS}

The authors acknowledge the pulp mill Sniace for providing the pulp needed for the experiments and analyses, and also for the use of the laboratories when needed.

\section{REFERENCES}

Andrade MF, Colodette JL (2014) Dissolving pulp production from sugar cane bagasse. Ind Crops Prod 52:58-64. https://doi.org/10.1016/j.indcrop.2013.09.041

Bahrami B, Behzad T, Zamani A, et al (2018) Optimal Design of Ozone Bleaching Parameters to Approach Cellulose Nanofibers Extraction from Sugarcane Bagasse Fibers. J Polym Environ 26:4085-4094. https://doi.org/10.1007/s10924-018-1277-5

Behin J, Zeyghami M (2009) Dissolving pulp from corn stalk residue and waste water of Merox unit. Chem Eng J 152:26-35. https://doi.org/10.1016/j.cej.2009.03.024

Borrega M, Larsson PT, Ahvenainen P, et al (2018) Birch wood pre-hydrolysis vs pulp post-hydrolysis for the production of xylan-based compounds and cellulose for viscose application. Carbohydr Polym 190:212-221. https://doi.org/10.1016/j.carbpol.2018.02.064

ChaoJun W, ShuFang Z, ChuanShan Z, DaiQi W (2014) Improved reactivity of bamboo dissolving pulp for the viscose process: post-treatment with beating. BioResources 9:3449-3455. https://doi.org/10.15376/biores.9.2.3449-3455

Chen C, Duan C, Li J, et al (2016) Cellulose (dissolving pulp) manufacturing processes and properties: A mini-review. BioResources 11:5553-5564. https://doi.org/10.15376/biores.11.2.Chen

Christoffersson KE, Sjostrom M, Edlund U, et al (2002) Reactivity of dissolving pulp: characterisation using chemical properties, NMR spectroscopy and multivariate data analysis. Cellulose 9:159-170. https://doi.org/10.1023/A:1020108125490

Dinand E, Vignon M, Chanzy H, Heux L (2002) Mercerization of primary wall cellulose and its implication for the conversion of cellulose I $\rightarrow$ cellulose II. Cellulose. https://doi.org/10.1023/A:1015877021688 
Duan C, Verma SK, Li J, et al (2016) Combination of mechanical, alkaline and enzymatic treatments to upgrade paper-grade pulp to dissolving pulp with high reactivity. Bioresour Technol 200:. https://doi.org/10.1016/j.biortech.2015.10.067

Duan C, Li J, Ma X, et al (2015) Comparison of acid sulfite (AS)- and prehydrolysis kraft (PHK)-based dissolving pulps. Cellulose 22:4017-4026. https://doi.org/10.1007/s10570-015-0781-1

Duan C, Wang X, Zhang YL, et al (2017) Fractionation and cellulase treatment for enhancing the properties of kraft-based dissolving pulp. Bioresour Technol 224:439-444. https://doi.org/10.1016/j.biortech.2016.10.077

Fardim P (2011) Chemical Pulping part 1. Fibre Chemistry and technology. 2nd Edition. Ed Pedro Fardim \& Abo Akademi

Fock W (1959) A modified method for determ ining the reactivity of viscose-grade dissolving pulps. Das Papier 13:92-95.

FZ/T 50010.13-2011, Pulp Board for Viscose Fiber- Determination for Reaction Property. China National Standards Press, Beijing (2011).

Gehmayr V, Schild G, Sixta H (2011) A precise study on the feasibility of enzyme treatments of a kraft pulp for viscose application. Cellulose 18:479-491. https://doi.org/10.1007/s10570-010-9483-X

Gondhalekar SC, Pawar PJ, Dhumal SS, Thakre SS (2019) Mechanism of xanthation reaction in viscose process. Cellulose 26:1595-1604. https://doi.org/10.1007/s10570-018-2213-5

Grönqvist S, Hakala TK, Kamppuri T, et al (2014) Fibre porosity development of dissolving pulp during mechanical and enzymatic processing. Cellulose 21:36673676. https://doi.org/10.1007/s10570-014-0352-x

Haule LV (2016) Iodine Sorption Value and Surface Chemical Analysis of Regenerated Cellulosic Fibres. J Text Sci Technol 02:37-45. https://doi.org/10.4236/jtst.2016.22006

Huang YM, Zhou MX, Xu CS, et al (2012) Production practice of bagasse pulp ECF bleaching. Chung-kuo Tsao Chih/China Pulp Pap

Iakovlev M, Sixta H, Van Heiningen A (2011) SO 2 -ethanol-water (SEW) pulping: II. Kinetics for spruce, beech, and wheat straw. J Wood Chem Technol 31:250-266. https://doi.org/10.1080/02773813.2010.523162

Ibarra D, Köpcke V, Ek M (2010) Behavior of different monocomponent endoglucanases on the accessibility and reactivity of dissolving-grade pulps for viscose process. Enzyme Microb Technol 47:355-362. https://doi.org/10.1016/j.enzmictec.2010.07.016 
ISO 5351. (2010). "Pulps - Determinations of limiting viscosity number in cupriethylenediamine (CED) solution solution," International Organization for Standardization, Geneva, Switzerland.

Ji L, Zhao L (2015). Current situation and future trend of the dissolving market in domestic and international. China Pulp Paper Industry, 36, 41-45

Jour P, Halldén K, Wackerberg E (2015) Life cycle assessment of ECF bleaching sequences with focus on carbon footprint. Tappi Journal, 14(1), 17-24.

Kaur P, Bhardwaj NK, Sharma J (2017) Pentosan Reduction from Mixed Hardwood Kraft Pulp with Alkali Treatment and Its Statistical Optimization. Lignocellulose 6:23-35

Kolar J (1997) Mechanism of autoxidative degradation of cellulose. Restaurator 18: 163176. https://doi.org/10.1515./rest.1997.18.4.163

Köpcke V (2010) Conversion of Wood and Non-wood Paper- grade Pulps to Dissolvinggrade Pulps

Kumar AK, Sharma S (2017) Recent updates on different methods of pretreatment of lignocellulosic feedstocks: a review. Bioresour Bioprocess 4:7. https://doi.org/10.1186/s40643-017-0137-9

Kumar H, Christopher LP (2017) Recent trends and developments in dissolving pulp production and application. Cellulose. https://doi.org/10.1007/s10570-017-1285-y

\section{Lewin M (2006) Handbook of Fiber Chemistry}

Li H, Legere S, He Z, et al (2018a) Methods to increase the reactivity of dissolving pulp in the viscose rayon production process: a review. Cellulose 25:3733-3753. https://doi.org/10.1007/s10570-018-1840-1

Li P, Hou Q, Zhang M, Li X (2018b) Environmentally friendly bleaching on bamboo (Neosinocalamus) kraft pulp cooked by displacement digester system. BioResources 13:450-461. https://doi.org/10.15376/biores.13.1.450-461

Liu Y, Shi L, Cheng D, He Z (2016) Dissolving pulp market and technologies: Chinese prospective - a mini-review. BioResources 11:7902-7916. https://doi.org/10.15376/biores.11.3.Liu

Llano T, Arce C, Ruiz G, et al (2018) Modelling and optimization of the last two stages of an environmentally-compatible TCF bleaching sequence. BioResources 13:66426662. https://doi.org/10.15376/biores.13.3.6642-6662

Loureiro PEG, Domingues EF, Evtuguin D V., Carvalho MGVS (2010) ECF bleaching with a final hydrogen peroxide stage: Impact on the chemical composition of Eucalyptus globulus kraft pulps. BioResources 5:2567-2580

Martínez AT (2016). How to break down crystalline cellulose. Science, 352:1050-1051. https://doi.org/10.1126/science.aaf8920 
Miao Q, Tian C, Chen L, et al (2015) Combined mechanical and enzymatic treatments for improving the Fock reactivity of hardwood kraft-based dissolving pulp. Cellulose 22:803-809. https://doi.org/10.1007/s10570-014-0495-9

Nayeem J, Sarkar M (2017) High purity dissolving pulp from jute. https://doi.org/10.3183/NPPRJ-2017-32-04-p623-629

Östberg L, Håkansson H, Germgård U (2012) Some aspects of the reactivity of pulp intended for high-viscosity viscose. BioResources 7:743-755

Payne CE, Wolfrum EJ (2015) Rapid analysis of composition and reactivity in cellulosic biomass feedstocks with near-infrared spectroscopy. Biotechnol Biofuels 8:. https://doi.org/10.1186/s13068-015-0222-2

Quintana E, Valls C, Vidal T, Roncero MB (2015) Comparative evaluation of the action of two different endoglucanases. Part I: On a fully bleached, commercial acid sulfite dissolving pulp. Cellulose. https://doi.org/10.1007/s10570-015-0623-1

Rebuzzi F, Evtuguin D V. (2006) Effect of glucuronoxylan on the hornification of Eucalyptus globulus bleached pulps. Macromol Symp 232:121-128. https://doi.org/10.1002/masy.200551414

Roselli A, Hummel M, Monshizadeh A, et al (2014) Ionic liquid extraction method for upgrading eucalyptus kraft pulp to high purity dissolving pulp. Cellulose 21:36553666. https://doi.org/10.1007/s10570-014-0344-x

Salazar C, Mendonça RT, Baeza J, Freer J (2012) Polpação kraft e branqueamento ECF de eucalyptus globulus pretratado pelo fungo de degradação branca ceriporiopsis subvermispora. Acta Sci - Technol 34:277-281. https://doi.org/10.4025/actascitechnol.v34i3.12410

Sango C, Kaur P, Bhardwaj NK, Sharma J (2018) Bacterial cellulase treatment for enhancing reactivity of pre-hydrolysed kraft dissolving pulp for viscose. 3 Biotech 8:1-7. https://doi.org/10.1007/s13205-018-1293-0

Sixta H (2006). Pulp properties and applications. In: Sixta H (ed) Handbook of pulp. Wiley-VCH., Weinheim, pp 1009-1067

Sixta H, Schild G (2009) a New Generation Kraft Process. Lenzinger Berichte 87:26-37

Sixta H, Iakovlev M, Testova L, et al (2013) Novel concepts of dissolving pulp production. Cellulose 20:1547-1561. https://doi.org/10.1007/s10570-013-9943-1

Strunk P (2012) Characterization of cellulose pulps and the influence of their properties on the process and production of viscose and cellulose ethers. Doctoral dissertation, Umeå University, Sweden.

TAPPI T203 cm-99. (1999). “Alpha-, beta- and gamma-cellulose in pulp," TAPPI Test Methods, TAPPI Press, Atlanta, GA. 
TAPPI T205 sp-02. (2002). "Forming handsheets for physical test of pulp," TAPPI Test Methods, TAPPI Press, Atlanta, GA.

TAPPI UM 246. (1991). "Micro kappa number," TAPPI Useful Methods 1991, TAPPI Press, Atlanta, GA, pp. 43-44.

Tian C, Zheng L, Miao Q, et al (2014) Improving the reactivity of kraft-based dissolving pulp for viscose rayon production by mechanical treatments. Cellulose 21:36473654. https://doi.org/10.1007/s10570-014-0332-1

Tian C, Zheng L, Miao Q, et al (2013) Improvement in the Fock test for determining the reactivity of dissolving pulp. Tappi J 12:21-26

Tripathi SK, Bhardwaj NK, Ghatak HR (2019) Effect of introducing ozone prior to elemental chlorine free bleaching of wheat straw pulp on pulp, paper and effluent properties. Cellul Chem Technol 53:105-112

Wang H, Pang B, Wu K, et al (2014) Two stages of treatments for upgrading bleached softwood paper grade pulp to dissolving pulp for viscose production. Biochem Eng J 82:183-187. https://doi.org/10.1016/j.bej.2013.11.019

Wang X, Duan C, Zhao C, et al (2018) Heteropoly acid catalytic treatment for reactivity enhancement and viscosity control of dissolving pulp. Bioresour Technol 253:182187. https://doi.org/10.1016/j.biortech.2018.01.022

Yadollahi R, Dehghani Firouzabadi M, Resalati H, et al (2018) SO2-ethanol-water (SEW) and kraft pulping of giant milkweed (Calotropis procera) for cellulose acetate film production. Cellulose 25:3281-3294. https://doi.org/10.1007/s10570-0181802-7

Yamamoto M, Iakovlev M, van Heiningen A (2014) Kinetics of SO2-ethanol-water (SEW) fractionation of hardwood and softwood biomass. Bioresour Technol 155:307-313. https://doi.org/10.1016/j.biortech.2013.12.100

Yang S, Wen Y, Zhang H, et al (2018) Enhancing the Fock reactivity of dissolving pulp by the combined prerefining and poly dimethyl diallyl ammonium chloride-assisted cellulase treatment. Bioresour Technol 260:135-140. https://doi.org/10.1016/j.biortech.2018.03.119

Yaqoob N, Stack K, Nguyen KL (2010) TCF bleaching of Eucalypt kraft pulp with oxone. Appita J 63:381-386

Zhu S, Wu Y, Chen Q, et al (2006) Dissolution of cellulose with ionic liquids and its application: A mini-review. Green Chem 8:325-327. https://doi.org/10.1039/b601395c 